\title{
Can natural history collections support a connection to nature for young children and families?
}

\author{
Elaine Bates
}

\begin{abstract}
Recent studies indicate that contact with nature is important for children's development, and supports creativity, wellbeing, problem solving and empathy with nature as adults. Researchers raise concerns that this experience is being eroded by a decline in green spaces (especially in cities) and an increasingly risk averse society (Bragg et al.2013; Louv 2005; Moss 2012; Pretty et al. 2009).

Whilst direct experiences of nature may be increasingly rare for young children, Kellert's work on biophilia and child development (2005) suggests that indirect experiences with nature, such as those occurring during a museum visit, may be able to compensate for this. Within this context, Manchester Museum developed Nature Discovery (opened in December 2014), a gallery aimed at engaging under-5s and their parents with nature. As well as drawing from existing studies of young children in museums, the gallery responded to research carried out with local parents, young children and teachers. This research focused on documenting parent and child interactions during a series of child-led, family visits to the existing natural history galleries and further visits by different families to evaluate the new gallery (2015).

Using existing nature connection measures (Cheng and Munro 2012; Ernst and Theimer 2011), the results suggest that natural history objects can support a connection to nature, which may result in environmentally friendly behaviours in adulthood. Parent and child interaction is identified as a key characteristic of supporting a connection to nature and in supporting children's learning.
\end{abstract}

Key words: early years, natural history galleries, nature connection, families

\section{Introduction}

The phrase 'Nature Deficit Disorder' was coined by Richard Louv in his book, Last Child in the Woods (2005), in which he asserts that children have become disconnected from the natural world as they have less opportunities to experience it. He raises concerns that a lack of opportunities in large urban cities to play in 'wild' natural spaces could adversely affect children's physical and cognitive development, wellbeing, creativity and problem solving. Also, that the children will have less empathy with nature and less interest in caring for it, when they become adults.

Similar concerns have been expressed in studies in the United Kingdom (RSPB 2010; Moss 2012; Bragg et al 2013). Moss's report for the National Trust led to the Natural Childhood Inquiry (2012) and the setting up of the Natural Childhood Partnership to promote opportunities for natural play for young children. A health report by Pretty et al (2009), highlighted the financial cost in the United Kingdom and worldwide for treating obesity and mental health problems linked to poor diet and less active lifestyles. The authors advocate that an increase in physical activity, especially in a natural environment, can have a positive effect on health and wellbeing. Longitudinal studies from this research show that exposure to play in natural environments in childhood has been linked to changes in attitudes and lifestyles in adulthood which may include dispositions for caring for nature. 
A key theory which explores the human relationship with nature is 'The Biophilia hypothesis' (Wilson1993; Kellert 2005). The basis of the hypothesis is that a natural bond between humans and all living things is part of our genetic makeup and as such, our physical and mental wellbeing depends on the quality of our experiences with nature. Kellert, a Professor of Social Ecology (at the Yale School of Forestry \& Environmental Studies) developed a set of 'biophilic' values $(2005 ; 2012)$, which explore different ways that humans interact with nature. This had been used as a framework to underpin the design of the Living Worlds gallery at Manchester Museum, in order to provide a range of opportunities for visitors to engage with the collections based on their prior experience of nature (McGhie 2012). For example, a case entitled, 'Connect' contains 3 dioramas of British predators, jungle animals and a polar bear. The display is linked to the biophilic value of 'affection' and its aim is to encourage visitors to think about how their choices and actions might impact on the natural world.

Kellert $(2005 ; 2012)$ states that experiences in nature are particularly important in early childhood, as they affect all areas of children's development, including emotional, intellectual and evaluative development. In his exploration of the quality of contact with nature in relationship to child development, Kellert categorizes children's experiences as being 'direct', 'indirect' and 'vicarious'. 'Direct' experience with nature is defined as playing outdoors in wild natural spaces. 'Indirect' experience with nature includes playing in gardens, outdoor play areas, parks or visiting wild life parks, zoos and natural history museums. Examples of 'vicarious' encounters with nature would be through reading books, looking at images and watching television or films. With a decline in opportunities for children for children in urban cities to have 'direct' encounters with nature, Kellert poses the question of whether or not an increase in opportunities for 'indirect' and 'vicarious' encounters with nature can help to compensate for this. Within this context, a natural history gallery, Nature Discovery, was redeveloped in 2014 for children aged under five and their families, who are a key audience for Manchester museum.

To underpin the development of the gallery, research was undertaken with six families (with children aged between 18 months to five years), an early years teacher and with parents attending a programme for young babies at the museum The focus of the research was to explore how the natural history collections can be used with young children and families to promote a sustainable world, which is one of the strategic aims of the museum as set out in The Manchester Museum Strategic Plan (2015-18) (Bates 2014). The study provided an opportunity to find out more about young children's experiences with nature and to document their responses to natural history collections, in order to use them more effectively to facilitate a connection to the natural world. In the following year, when the gallery had opened, a further study was carried out with four different families and two volunteers (recruited to work specifically in the gallery to pilot object handling activities with young children). The focus of this study was to evaluate how well the new gallery was facilitating parent and child interactions and to identify what further interpretation was needed to facilitate families learning together about nature (Bates 2015).

\section{Museum research with children aged under 5}

Museum professionals have acknowledged that studies with young children is an under researched area (Piscitelli and Anderson 2000; Dunn 2012; Kirk 2013). Kirk in particular states, 'There is a lack of literature about the everyday experiences of young British children visiting natural history museums with their families' (2014: 7).

Existing studies documenting young children's experiences and responses to natural history collections (Piscitelli and Anderson 2000; 2002; Tunnicliffe and Reiss 2000; Dockett et al. 2011; Dunn 2012; Kirk 2013) find that young children's visits to museums are negotiated in a very individual way. Their recall of favourite objects, even with children visiting in a group, are very diverse, as this is mediated by their prior knowledge and experience of the natural world and the adults or social groups they visit with. A general theme running through these studies is that young children are fascinated by natural history objects which are both familiar and unfamiliar to them. They have empathy, for example, with a cat or squirrel, but are also drawn to animals that they may be afraid of, for example a snake, a tiger, or animal with sharp teeth and claws. They also respond to objects that are novel and appeal to their sense of humour and that are 
big or small, including dinosaurs, skeletons, large animals and insects. Being able to explore objects through the sense of touch is important for young children, but Kirk (2013) reports that being able to get up close to the objects is the key to a memorable experience for this age group. Crowley and Jacobs (2002) found that the opportunity to engage with life size representations of objects from the natural world in an unusual and memorable setting like a museum, have a unique role in supporting children to develop specialized knowledge about things which interest them, for example dinosaurs and animals. They use the term 'islands of expertise' to describe intense interests in particular objects which children develop over a period of time and that parental interaction is key to supporting and mediating this learning.

\section{Families learning together in museums}

Most research studies documenting family visits to museums undertaken in the United States of America conclude that the main reasons for visits are to share social experiences and to learn together (Ash 2003; Dierking 1989; Haden 2010; Henderson and Atencio 2007; Melber 2007; Nadelson 2013; Puchner et al. 2001; Wolf and Wood 2012). Moran, in an examination of family learning in different countries, defines family learning as 'adults and children learning together. It is collaborative learning in a social context' (2010: 70). Ash states, 'Museums are places where families play, talk and learn from each other' (2003: 138). Studies find that the particular mechanism which enables children's learning is the active support of their parent or caregiver in the form of questioning, explanation or guidance (Crowley and Jacobs 2002; Dooley and Welch 2013; Dunn 2012; Fender and Crowley 2007; Haas 1997; Haden 2010; Melber, 2007; Nadelson 2013; Palmquist and Crowley 2007; Puchner et al. 2001; Wolf and Wood 2012). For example, Crowley and Jacobs (2002) analyzed family conversations about fossil identification in a children's museum and found that children who had received more support from parents were able to identify more fossils. Their studies showed that this was particularly true for younger children, who were able to identify about half of the objects they encountered on a museum visit, even if parents provided only low levels of mediation and that this increased as parental mediation increased. Wolf and Wood state, 'Positive effects on children's learning cycles clearly emerged as an outcome of active adult guidance' (2012: 30).

\section{Indicators of nature connection}

A key indicator of connection to nature is evidenced through young children's emotional responses to the natural world. Kellert (2005) finds that children's affective responses (both positive and negative) are important in mediating their experience of nature, both as children and adults. Similarly, White and Stoecklin (2008), in a study relating to biophilia and environmental education programmes for children, assert that young children's affective attitudes towards nature develop before their more logical, cognitive processes so that regular and positive interactions with nature can support the development of positive environmental behaviours in adulthood. Sebba et al. (in Kellert 2005) and Chawla (2009) cite examples of self-reported affective experiences with nature in childhood and youth which inspired creativity and proenvironmental behaviour in adulthood.

The view that 'indirect' experience of nature (for example, through visits to natural history museums) can increase opportunities for children to engage with nature, is also supported in several studies. Kimble (2013), documenting visits by children (eight to nine years) to a natural history gallery, (as well as an environmental centre and live animal show) found that the museum visit supported an affective connection to nature and helped to raise awareness about nature. In a study documenting responses from young children and families visiting a simulated natural area which was part of a children's exhibit at Brevard Zoo in Florida (Oxarart et al. 2013), the authors report promising evidence that 'indirect' experience of nature increased opportunities for children to engage in natural play. Staff used play prompts in order to increase parent's confidence and participation in natural play with their children and a follow up study showed that there had been an increase in visits by families to local green spaces.

Recent studies have also looked at developing instruments which specifically try to measure a connection to nature. Ernst and Theimer (2011) reviewed a range of these studies 
and identified three aspects within existing questionnaires which were common in measuring a connection to nature. These were: affective responses (emotions and feelings towards nature); cognitive responses (knowledge and beliefs about nature); and behavioural responses (actions and experiences in nature). One of these studies, Cheng and Munro's 'Connection to Nature Index' (2010), designed to be used with children aged eight to ten years, was trialled in a study undertaken by The University of Essex and the Royal Society for the Protection of Birds (2013) to measure a connection to nature with children in outdoor environments, including their enjoyment of, empathy with and sense of responsibility towards nature. In a follow up study, Cheng and Monroe (2012) identified indicators of nature connection in childhood which could be used to predict environmentally friendly behaviours in adulthood. In summary, they found that: incremental, positive experiences in nature increased children's connection to nature; it was important for children to feel that their small actions could make a positive difference in taking action to protect nature; children from families who took an interest in nature, were more likely to be interested in caring for the environment in adulthood. The outcomes of their research were important for my study as they identify affective nature connection indicators which museum visits can support, including engaging parents with nature and helping them to support their children's interest in nature. A small study (with five families) was undertaken to document young children's responses to the collections during self-led visits to the natural history galleries with their families which would underpin the development of Nature Discovery gallery.

\section{Methodology}

Families were recruited to the studies at Manchester Museum through early years programmes at the museum and by working in partnership with a local children's centre. Practitioner research was undertaken, which is referred to as 'real world research' (Robson 2011: 3) and within the developing paradigm of praxeological research (Pascal and Bertram 2012). Qualitative methods were used to document research undertaken in the museum and the studies were presented as evaluative case studies (Yin 2003). Data collection methods included: collecting written observations and audio recorded parent and child responses to the collections and conducting informal interviews with an early years practitioner and volunteers.

My position was that of a participant observer, fully involved in research activities which afforded the opportunity to ask supplementary questions and clarify the context particularly in relation to adult and child responses.

The 'European Early Childhood Education Research Association Ethical Code for Early Childhood researchers' (EECERA 2015) was used as a checklist to reflect on the ethical implications of the studies and to inform research design. Some of the key ethical issues addressed were: voluntary and informed consent of participants; inclusive participation; confidentiality; no harm; participants seen as subjects; justification and value of the research; participatory approaches; feedback to all participants; dissemination of the research.

All participants invited to take part in the research were informed from the outset that their participation was purely on a voluntary basis and that they had the right to withdraw their consent and participation in the study at any time without justification. Informed verbal and written consent was sought at the beginning and throughout the research activities from adults for themselves and for their children. Direct verbal and nonverbal assent (or dissent) was also sought directly from children using developmentally appropriate methods documented in recent studies (Dockett et al. 2009; 2012; Dockett et al. 2011; Phelan and Kinsella 2013). For example, very young children were offered images of smiley faces, sad smiley faces and neutral smiley faces to aid nonverbal communication of assent or dissent to take part in research activities. In both studies, visits were led by the families who were free to leave the natural history galleries at any time and continue their visit in the rest of the museum.

The audio recorded conversations and observations for each of the parent and child visits were transcribed, in order to analyze children's verbal and nonverbal responses to the natural history collections. For example, some children were able to talk about the objects, including naming them, or offered knowledge or prior experience about the object. Some children simply responded with laughter, a squeal of delight or an 'aww!' in response to seeing some objects. One child, in response to seeing the orangutan, said: 'The big daddy is scary.' Some 
nonverbal responses to the objects included children jumping up and down with excitement, or returning repeatedly to the same object. Responses were analyzed using two of the key indicators for nature connection identified by Ernst and Theimer (2011); 'affective' or 'cognitive.' Also, Kellert's (2005) three categories of 'direct', 'indirect' and 'vicarious' were used to analyze children's prior experience of nature. I added the category of 'none' if the children indicated an interest in a natural history object they had no prior knowledge or experience of (according to their caregiver). The second stage of analysis was to produce a short case study summary of each child's individual visit and to extrapolate recurring themes in the children's responses in order to make some general observations about their experiences on the visits.

\section{Young children's experiences in the Living Worlds gallery, Nature's Library gallery and the Vivarium at Manchester Museum (2014)}

The data from the family visits in the first study (Bates 2014), evidenced a range of characteristics across a broad developmental age range (with six children aged between 17 months to four and a half years) about their experiences on the existing natural history galleries. The average length of visit for the children aged three was 30 minutes. The two children under two years old who were walking, but were less verbal than the other children, spent more time physically exploring the museum spaces (for example walking up and down the stairs) and their visits were slightly longer (45 minutes). All the children's visits were negotiated in a very individual way and they visited a wide range of objects (72 in total).

Some children visited the same object more than once. The most visited objects included apes, birds, skeletons/ skulls and familiar animals from stories (including: fox; lion; tiger; badger; and hedgehog) or within children's direct and indirect experience, for example, the frogs and tadpoles in the Vivarium which children had encountered in nursery school, or the birds in the garden. Children also showed an interest in a range of unfamiliar objects which they found unusual or novel or that they were apprehensive of, for example, the reticulated python. Interestingly, research by Tobias (1994) finds that there is a relationship between interest and prior knowledge. He concluded that although prior knowledge may be a motivator for learning, interest may also play as important a role in supporting learning which is reflected in the range of objects children chose to visit.

Objects such as the whale skeleton and paper cranes were interpreted in different ways by the children, linked to their individual interest and experience. For example, the whale skeleton was a 'dinosaur' to one child; a display of paper cranes were interpreted as either dinosaurs, ducks or airplanes by different children. Novel objects such as a goat displayed in a woolly jumper, appealed to the children's sense of humour and made then laugh. A full summary of all objects visited and individual case studies summarizing the objects each child visited is included in my original study (Bates 2014). Children's affective responses to the collections were mostly positive, which is a key indicator of nature connection in existing measures and is associated with caring for nature in adulthood (Cheng and Munro 2012; Ernst and Theimer 2011; Kellert 2005). Some children exhibited negative responses, for example, by hiding behind their caregiver, to objects such as the reticulated python (which is enormous) and the orangutan (exhibited in a fierce pose) which are perhaps less friendly versions of the animals they have previously encountered through stories or images. Kellert (2005) asserts that a negative response towards some aspects of nature is a normal characteristic of young children's affective development. In this context, the museum might be considered to be a safe space in which to experience aspects of nature that young children may be afraid to encounter directly in the natural world.

Kellert's (2005) three categories of children's experience with nature were used to document and analyze children's prior experiences with the nature they encountered on the natural history galleries. A total of 188 responses to objects were recorded using the category headings 'direct experience' (12 per cent of responses), 'indirect experience' (17 per cent of responses), 'vicarious experience' (51 per cent of responses) and 'no previous experience' (20 per cent of responses) when children showed interest in an object they had not previously encountered. Responses to objects categorized as 'vicarious' experiences (from stories, film, television, and images) evidenced the most responses (51per cent). For example, one child associated a chimpanzee on display with reading the book Dear Zoo (Campbell 2011) and 
another child associated the fox with reading Beatrix Potter books. This is significant in terms of affirming our current practice with young children at the museum, as we use stories as a vehicle to engage and facilitate a connection to the collections, supported by sensory resources and opportunities to handle real objects. 'Indirect' experience of nature (17 per cent of responses), for example, was evidenced through children's experience of learning about tadpoles in a nursery class or preschool setting. One example of children's 'direct' experience of nature (12 per cent of responses), was that a child had encountered bats on a family camping trip. Children also encountered objects which they had no previous experience of (20 per cent of responses) but which they were interested in, for example a pangolin, armadillo or anteater.

Importantly, museum visits provide children with opportunities to engage with a variety of nature which is both familiar and unfamiliar and which they would not necessarily be able to encounter directly in the real world. The early years practitioner I interviewed commented, 'Many children come from deprived or secluded backgrounds. They don't know what they are interested in until they see a range of things. Some of the boys were interested in dinosaurs but when they went to the museum they were interested in other things like the polar bear and gorilla' (Bates 2014). He also reported that museum visits provide opportunities to experience nature that children cannot fully experience through books and images and which help them to make connections to the natural world, commenting,

You can show a picture or a Powerpoint (of a tiger). In the museum you get a sense of size and awe standing next to it. In a safari park it would be scary! Children understand that tigers don't live in Manchester but we learn about the rain forest and the air we breathe-trees make the air. The museum helps us to make the big connections (Bates 2014).

A full summary of data collection, transcription and analysis is included in my original study (Bates 2014).

Overall, these findings broadly relate to the experiences of young children visiting natural history museums documented in existing studies (Piscitelli and Anderson 2000; 2002; Tunnicliffe and Reiss 2000; Dockett et al. 2011; Dunn 2012; Kirk 2013). In summary these are: young children's visits are negotiated in an individual way; natural history objects popular with young children include big and small objects, familiar, unfamiliar and novel objects or objects which they may be fearful of but hold a fascination for them.

My research evidences the importance of parent and child interactions in helping children to connect to the collections. For example: by naming objects for the child; prompting children about prior experiences of the object; physically supporting children to get closer to objects by lifting them up to explore objects in cases higher than themselves. Importantly, Cheng and Munro (2012) find that children from families whose parents have an interest in nature are more likely to care for nature. However, the early years practitioner highlighted that not all parents from the setting where he works are confident museum goers and need help to support their children's interest in and learning about nature. He commented, 'Parents are either embarrassed to engage or frightened. They need to know that there is no right or wrong answer but just have an open mind. Don't tell them what to think but give them pointers' (Bates 2014)

\section{Developing the Nature Discovery gallery: research into practice}

The key themes of the research relating to children's different experiences of nature, using the Kellert (2005) categories of 'direct', 'indirect,' 'vicarious,' and an added category of 'no previous experience', together with children's affective responses to objects, were used to underpin the design of the Nature Discovery gallery. Objects were chosen which directly related to each of the categories of young children's experiences of nature and we created four distinct exhibit areas which reflect the real life environments of the chosen natural history objects.

For example, two areas of the gallery, the 'Tree Tops' and the 'Meadow' areas, reflect nature with which young children are familiar through their everyday experience in nursery, in the home or visiting parks. The 'Meadow' area contains many objects which are familiar to young children, including butterflies, insects and plants. There are different levels to explore with creatures above and below 'ground'. In the 'Tree Tops' area, the idea was to create a 'bird spotting' area, with common birds displayed in bird boxes and on a bird table. We hoped 
to use the gallery to signpost families to similar activities in outside spaces, including their own garden or in parks.

'The Den' area contains a case shaped like a tree trunk [Figure 1] containing animals that are familiar to children from U.K. stories, for example, a badger, squirrel, owl and rabbit. There is a bookcase nearby and families are encouraged to read stories together in this space. We worked with a paper sculpture artist (Helen Musslewhite) to create a story book setting in the 'Forest' case [Figure 2] in which to display a mixture of both familiar and unfamiliar British wildlife animals (for example, an owl and a baby wild boar) big and small animals (for example, a deer and a wood mouse) and nature that children may be fearful of in real life (for example, a wolf). The story book setting was designed to appeal to the imagination of young children and to provide starting points for children's own story making.

\section{Evaluating the Nature Discovery gallery}

During the first year the gallery was open, I undertook a follow up evaluative case study (Bates 2015) to explore the research question, 'Nature Discovery: How can museums

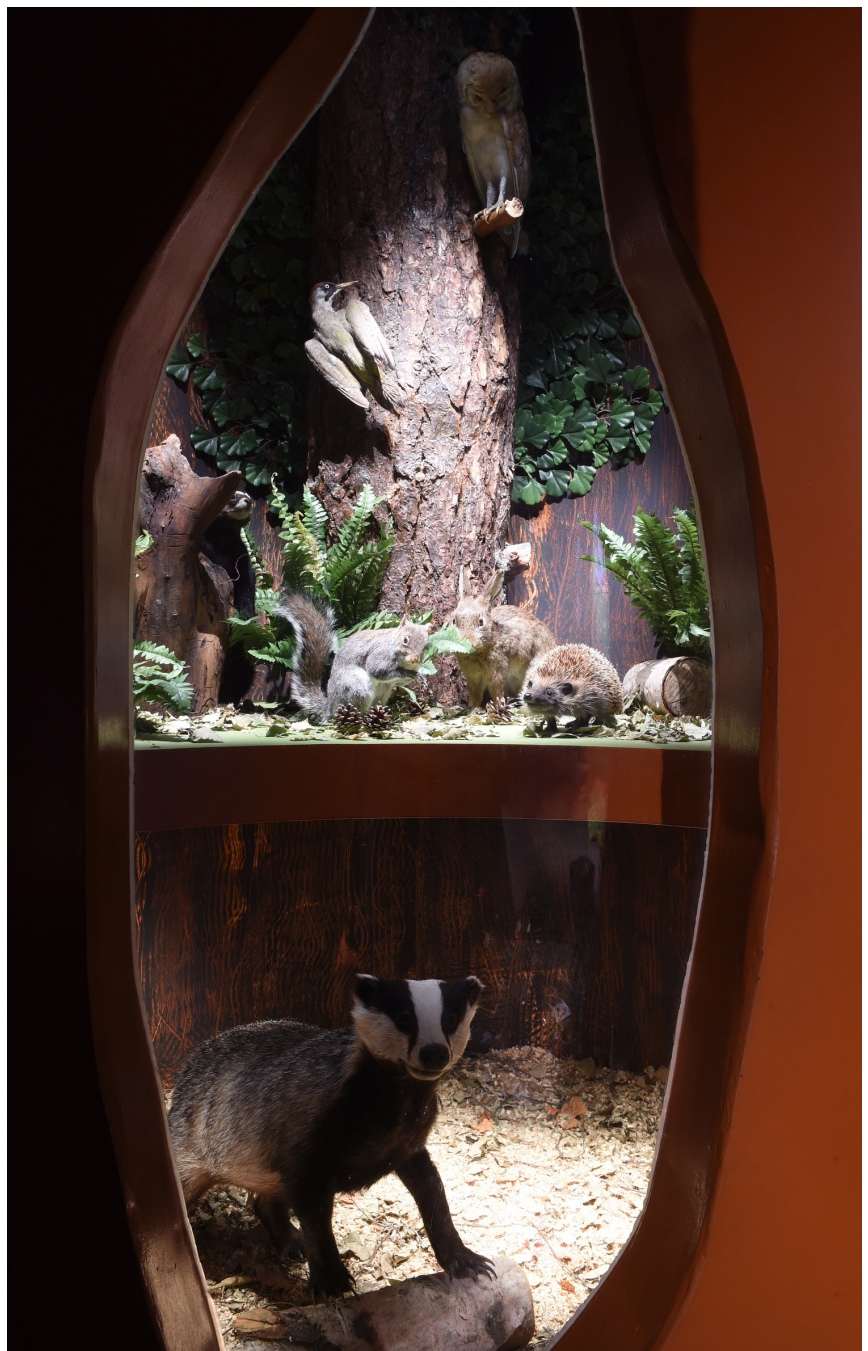

Fig 1. 'Den', Nature Discovery Gallery, Manchester Museum. Photo by author better support interactions between parents and young children.' The aim of the study was to analyze and understand the nature and content of parent and child interactions in the new gallery in order to pilot different interpretation strategies which would support them. We had made a conscious decision not to include labels for the objects in the cases or to provide text panels. Graphic panels providing a description and welcome to each of the areas was the only interpretation provided. This was partly for aesthetic reasons and also because we wanted to test out different forms of interpretation which would be more appropriate and interactive for young children. For example, we had recruited a small team of dedicated volunteers to engage with families directly in the space to pilot object handling activities. We trialled simple sheets containing up to six images of the Nature Discovery objects, to encourage parents and children to play an 'I Spy' game to find them around the gallery. Simple tools such as binoculars and magnifiers were available to support this kind of playful activity. 


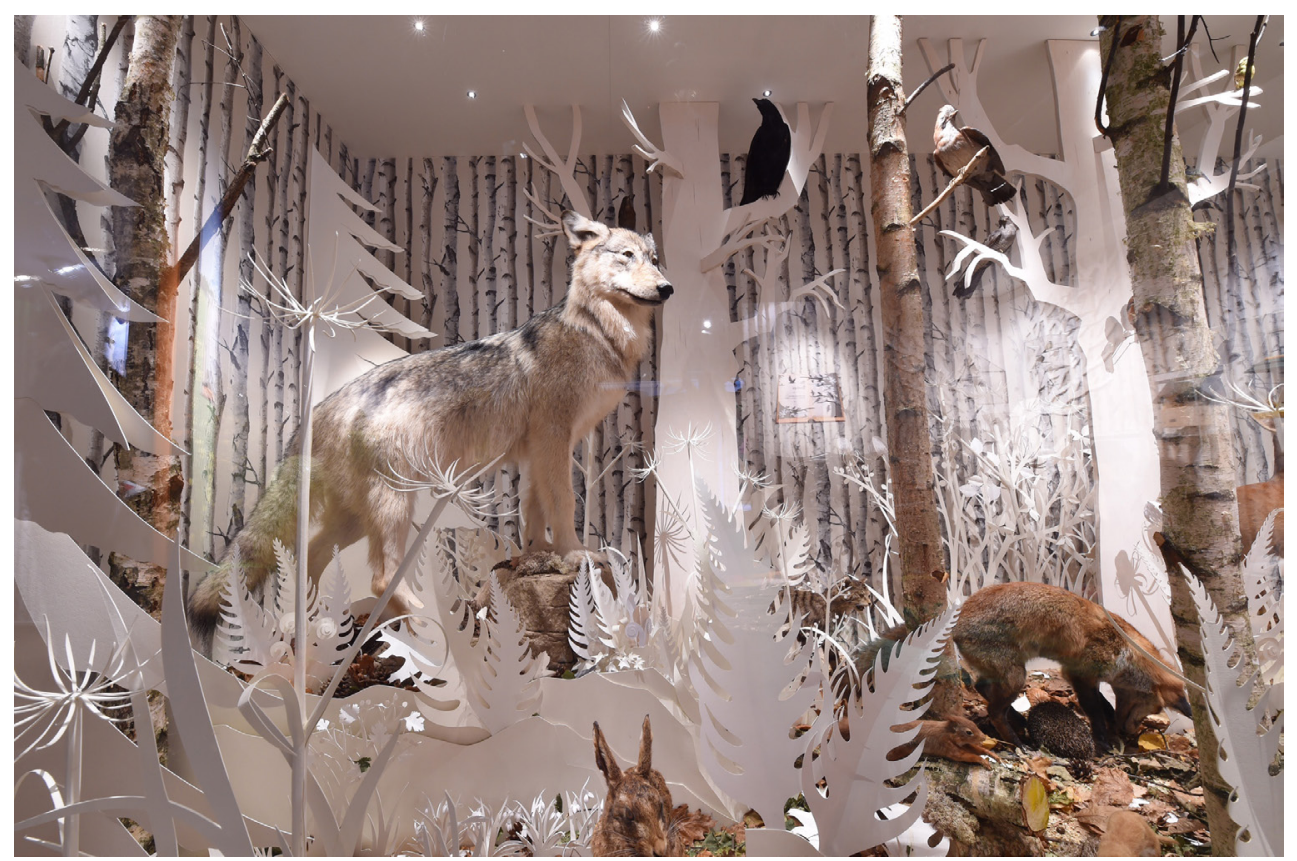

Fig 2. 'Forest', Nature Discovery Gallery, Manchester Museum. Photo by author

\section{The nature of parent and child interactions}

Dooley and Welch (2013) analyzed the range and frequency of adult and child interactions during museum visits. They found that children and adults are equally likely to lead interactions, but that the nature of the interactions are different. The most frequent child led interactions were categorized as 'Show and tell' (2013: 129). These interactions included drawing attention to, labelling or commenting on an object. Children also initiated learning conversations by asking questions or prompting answers from parents. The most frequent adult led interactions were categorised as 'Teaching'. These interactions included explaining, prompting, labelling, modelling activities and commentating on children's actions (2013: 130).

Studies which looked more specifically at the nature of adult interactions with children report similar findings (Allen, 2002; Crowley and Jacobs, 2002; Fender and Crowley, 2007; Melber 2007). Other categories of interactions observed by Dooley and Welch (2013) included: 'Participatory play', defined as 'playing along' with an activity initiated by another family member. 'Refocusing' is defined as signalling a change in activity or desire to leave the gallery. Also, when children indicate that physical assistance is needed, or adults provide physical assistance due to the developmental needs of a child this is categorized as a 'Physical' interaction. Allen (2002: 274) analyzed the conversations of family groups visiting a museum and coded their interactions in categories of 'Learning talk'. Some of these categories are similar to those documented by Dooley and Welch (2013). 'Perceptual talk' for example, is similar to their category of 'Show and tell' interactions. 'Conceptual talk' on the other hand, includes interactions which evidence knowledge or understanding of an object beyond naming them. 'Affective talk' interactions include evidence of feelings about an object (negative or positive). 'Connecting talk' interactions are characterized by reference to prior experience in life, knowledge, or with another exhibit. Crowley and Jacobs (2002) also attach high importance to adult teaching strategies which build on children's prior experience to extend their knowledge. All of these categories were used to code and analyze the conversations of families recorded during gallery visits (Bates 2015).

Research visits were undertaken with four new families with children aged three years (including one family with a younger sibling aged four months). Their responses to and 
interactions in the new gallery were observed and recorded. In addition, two volunteers who were facilitating the new gallery, were interviewed in order to gain their perspective of parent and child visits to the gallery (Bates 2015).

\section{Summary of research outcomes}

Having examined all the data I was able to make the following general observations from the visits. All the gallery areas were visited by the families and had objects which were a focal point for young children, but 'The Meadow' was the most visited area of the new gallery by families, who were able to identify most of the objects without further interpretation. Interestingly, the 'Tree Tops' area was visited less by the families and volunteers suggested that this might be because some parents were less confident about naming the birds and that basic information about the objects would be welcome. Accordingly, volunteers had noticed that children visiting with grandparents tended to stay in this area longer, as these accompanying adults were more likely to know the names of the birds. Observations and feedback suggested that the gallery was generally being enjoyed by adults as well as children and this was an important aim during the design process as parents who are engaged with exhibitions themselves, are more likely to directly engage with their children on gallery visits. One of the volunteers commented,

Some adults and grandparents like to come in without children and sit and look because it is a pretty and nice space.... It's not like it's completely for children and full of children's stuff. So they don't feel like they need to leave (Bates 2015).

Affective responses to the objects in the new gallery were again mostly positive, which was evident through children's verbal and nonverbal responses such as smiling, pointing and trying to get closer to the case, or declaring 'I love those owls, I love those owls.' It was interesting to observe one child, who cautiously kept a distance between herself and some of the objects in 'The Meadow' area. Her mother had already told me that the child was 'afraid of insects.' This child chose to visit 'The Meadow' area twice and her mother reassured her that, 'they couldn't get out'. A few weeks later, the child's mother was attending a programme at the museum with her baby. She told me that after her encounter with the insects on the gallery, her daughter didn't seem to be as afraid of real insects and had been looking for them in the garden at home.

The majority of interactions could be categorized as 'Show and tell' for children and 'Teaching' for parents, which corresponds to the main categories documented in existing studies (Allen, 2002; Crowley and Jacobs 2002; Dooley and Welch 2013 Fender and Crowley 2007; Melber 2007). Children tended to name an object or give an observable detail about it. For example, 'He's stripy' (referring to a wild cat), or 'I can see a reindeer'. Some children did articulate knowledge about the objects beyond naming them, which were categorized as 'conceptual', for example, 'Badgers dig and eat worms'. They also tended to lead the 'Refocusing' interactions, by choosing the areas of the gallery and objects they wished to visit, using both verbal and nonverbal signals, for example, saying 'Look!' or leaving the gallery space. Some parents also used 'Refocusing' interactions for the purpose of keeping their child engaged in the gallery visit. The binoculars and magnifiers in the gallery were popular tools which helped children lead interactions and explore the gallery in a playful way. One of the parents initiated play as a strategy for keeping her child engaged in the gallery visit. She gave the child clues to find objects and initiated 'finding games' inviting the child to copy her 'sneaky walk'. The child also initiated play, asking his mum to guess which object he was thinking about, saying, 'Mum l'll give you a clue. It's red and begins with a b.'

Interactions initiated by parents mainly fell into the category of 'Teaching'. These strategies included prompting, naming, explaining, or using 'Connecting talk'. When children had chosen the area of the gallery or object they were interested in, parents used teaching strategies in order to elicit or impart knowledge to their children about the objects. For example, asking Where do these animals all live?' 'Who's down here?' 'Look! That's a mole!' 'Well they look like butterflies but they are called - are you ready? - Moths'.

Conversations evidencing 'Connecting talk', were mainly initiated by parents, as a teaching strategy to prompt children about prior shared experiences or knowledge, although some children also initiated this strategy. These conversations seemed to support longer 
gallery visits and were prompted by books that the adult and child had read together and prior experience or knowledge about the objects on display. For example, one conversation was prompted by the child seeing a copy of The Badger's Bath (Butterworth 1996) in the book area in the gallery, which led to a conversation about what the child knew about badgers, about a fox and a badger he had seen in the garden at home and prompted a badger hunt in the gallery. These conversations also prompted children to recount knowledge they had about the animals beyond naming them, categorized as 'Conceptual' interactions. Allen (2002) and Crowley and Jacobs (2002) suggest that conversations which link to and build on children's prior experience can support children's learning. Heuer (2013) examined the factors of prior knowledge and interest in engaging (adult) visitors attending an exhibition on Darwin (in two different locations) and found that having no prior knowledge of the exhibition theme (evolution) was not a barrier to engaging visitors and to them spending a long time in the exhibition.

\section{Conclusion and further developments}

The research produced a rich narrative about the families' experiences in the new gallery and evidenced the opportunities that it offers for supporting families to learn about nature together. However, findings suggested that families come to the museum with different levels of prior knowledge and experience and providing a range of interpretation could help to increase the duration of family visits which is important as Wolf and Wood (2012) find that increased opportunities for learning are associated with longer gallery visits. We have therefore continued to recruit volunteers to engage with families in the new gallery and have worked with them to develop a handling table with its own dedicated objects. These include objects displayed in the gallery itself (for example, an owl) and other objects which reflect the wider natural history collections (for example, a sea horse). The volunteers also have additional information about the objects in the gallery so that they can answer questions and support dialogue between parents and children. An 'I Spy Nature' leaflet is also available in the gallery, which includes a pair of 'tear off' binoculars for spotting animals on the gallery itself (and in the wider museum) as well as prompts for other activities that families can do together (for example, reading together). We also use the gallery as a base for our early years family programmes, 'Baby Explorers' and 'Magic Carpet' and have developed new interactive story and music sessions which link directly to the objects and environments in the gallery. For example, one of the 'Baby Explorer' sessions is based on the animals in 'The Forest' area (supported by sensory resources reflecting the colours and the textures of the case content). One of the 'Magic Carpet' stories uses the theme of 'seasons' to introduce children to each of the four different environments in the gallery. The introduction of the handling table and the 'I Spy Nature' resource have particularly helped to support opportunities for families learning together on a self-led visit.

The museum has a small allotment on the courtyard leading to the museum entrance. In summer 2016, we held a weekly programme of events in this space targeted at families with young children. The activities were delivered in partnership with a range of organizations, including a local garden centre, the RSPB, an owl sanctuary and Lancashire Wild life Trust using a small amount of funding from a charitable trust. Activities included bird and insect spotting, den building and 'messy play' activities using pots, pans water, seeds and pulses. Families were also invited to make bird boxes and bug hotels to take away to encourage them to care for nature at home. Alongside the outdoor activities there was also a programme of nature related story sessions, music and performances in the gallery, as well as opportunities for object handling led by curators. The aim was to link nature in the gallery to nature outdoors and to signpost families to parks and other green spaces. This was a good opportunity to test out models of engagement and partnerships to inform our offer for families as part of a capital redevelopment project which will be realised in 2020. Clearly, the continued development of research methods and studies with young children is important in order to more fully understand their experiences in natural history museums and how interpretation strategies may support parent and child interactions. If ongoing research informs evolving changes to gallery interpretation, this creates a positive feedback loop of improved communication that benefits visitors and staff.

While a dedicated gallery for children under five is a great asset and resource for Manchester museum, this may not be possible for many other institutions. Developing an offer for children aged under five years and their adult companions should be integral to an 
institution's strategic aims and appropriate for the collections and audience. Practice will look different in each organization as each museum and gallery has unique collections and is funded differently. However, some key learning points from our experience of developing practice and engagement activities with this key audience can be extrapolated. The Manchester Museum examples I have shared demonstrate that ambitious results can be achieved at low cost by starting small. Developing sustainable and reciprocal relationships with local early years settings (within walking distance, if possible) will help interpretive staff to develop expertize in child development, pedagogy and practice with young children. In some cases, early years practitioners may be willing to help pilot and evaluate appropriate interventions, resources or programmes with young children and where possible encourage them to invite parents to accompany children on visits. New offers can be marketed using a variety of platforms appropriate to your local audience. In order to ensure sustainable delivery, documenting and continuing to learn from practice is vital. Sharing experiences with other early years settings, local stakeholders and other museums and gallery professionals enables a wider conversation about the benefits of catering to an overlooked audience to create exhibit spaces that work for everyone.

Received: 14 June 2018

Finally Accepted: 25 October 2018

\section{References}

Allen, S. (2002) 'Looking for Learning in Visitor Talk: a Methodological Exploration', in Gaea Leinhardt, Kevin Crowley, and Karen Knutson (eds.) Learning Conversations in Museums, 259-304, New Jersey: Lawrence Erlbaum.

Anderson, D., Piscitelli, B., Weier, K., Everett, M. and Tayler, C. (2002) 'Children's Museum Experiences: Identifying Powerful Mediators of Learning', Curator: The Museum Journal, 45 (3) 213-231 http://onlinelibrary.wiley.com/doi/10.1111/j.2151-6952.2002. tb00057.x/full.

Ash, D. (2003) 'Dialogic Inquiry in Life Science Conversations of Family Groups in a Museum' J. Res. Sci. Teach, 40 (2)138-162 http://doi.wiley.com/10.1002/tea.10069

Bates, E. (2014) 'Nature Discovery: Museums Using Natural History Collections to Support a Connection to Nature with Young Children and Families' Unpublished report submitted as part of MA. Education (Early Years), Birmingham City University.

(2015) 'Nature Discovery: How can Museums Better Support Parent and Child Interactions?' Unpublished report submitted as part of MA. Education (Early Years), Birmingham City University.

Bragg, R., Wood, C., Barton, J. and Pretty, J. (2013) 'Measuring Connection to Nature in Children Aged 8-12: A Robust Methodology for the RSPB' Royal Society for the Protection of Birds, http://visitwww.rspb.org.uk/Images/methodology-report tcm9354606.pdf

Butterworth, N. (1996) Tales from Percy's Park, London: Collins Children's.

Campbell, R. (2011) Dear Zoo, London: Macmillan Children's Books.

Chawla, L. (2009) 'Growing up Green: Becoming an Agent of Care for the Natural World' Journal of Developmental Processes, 4 (1) 6-23 https://peecworks.org/PEEC/ PEEC Reports/01795CA8-001D0211.34/jdpchawla.pdf

Cheng, J. and Monroe, M. (2012) 'Connection to Nature: Children's Affective Attitude Toward Nature' Environment and Behavior, 44 (1) 31-49 http://dx.doi. org/10.1177/0013916510385082 
Crowley, K. and Jacobs, M. (2002) 'Building Islands of Expertise in Everyday Family Activity' Learning Conversations in Museums, 333-356 http://www.museumlearning.org/mlc05a.pdf.

Dierking, L. (1989) 'The Family Museum Experience: Implications from Research' The Journal of Museum Education, 14 (2) 9-11 http://www.jstor.org/stable/pdf/40478807. pdf

Dockett, S., Einarsdottir, J. and Perry, B. (2009) 'Researching with Children: Ethical Tensions' Journal of Early Childhood Research, 283-298 http://ecr.sagepub.com/ content/7/3/283. short

Dockett, S., Main, S. and Kelly, L. (2011) 'Consulting Young Children: Experiences from a Museum' Visitor Studies, 14 (1) 13-33 http://dx.doi.org/10.1080/10645578.2011.557 $\underline{626}$

Dockett, S., Einarsdottir, J. and Perry, B. (2012) 'Young Children's Decisions About Research Participation: Opting Out' International Journal of Early Years Education, 20 (3) 244-256 http://www.tandfonline.com/doi/abs/10.1080/09669760.2012.715405

Dooley, C. and Welch, M. (2013) 'Nature of Interactions Among Young Children and Adult Caregivers in a Children's Museum' Early Childhood Education Journal, 42 (2) 125132 http://link.springer.com/10.1007/s10643-013-0601-x

Dunn, R. (2012) 'A Vision of History: Young Children's Perspective on a Museum,' in Peter Whiteman and Katey De Gioia (Eds.) Perspectives, Places and Practices (1st Edn), 151-186, Newcastle upon Tyne: Cambridge Scholars.

European Early Childhood Research Association, (2015) Ethical Code for Early Childhood Researchers http://www.eecera.org/documents/pdf/organisation/EECERA-EthicalCode.pdf

Ernst, J. and Theimer, S. (2011) 'Evaluating the Effects of Environmental Education Programming on Connectedness to Nature' Environmental Education Research, 17 (5) 577-598 http://dx.doi.org/10.1080/13504622.2011.565119

Fender, J. and Crowley, K. (2007) 'How Parent Explanation Changes What Children Learn from Everyday Scientific Thinking' Journal of Applied Developmental Psychology 28 (3) 189-210 http://linkinghub.elsevier.com/retrieve/pii/S0193397307000184

Haas, N. (1996) 'Project Explore: How Children are Really Learning in Children's Museums' Washington: Center for Advancement of Informal Science Education http:// informalscience.org/images/research/VSA-a0a0y3-a_5730.pdf

Haden, C. (2010) 'Talking About Science in Museums' Child Development Perspectives, 4 (1) $62-67$ http://onlinelibrary.wiley.com/doi/10.1111/j.1750-8606.2009.00119.x/full

Henderson, T. and Atencio, D. (2007) 'Integration of Play, Learning, and Experience: What Museums Afford Young Visitors?' Early Childhood Education Journal, 35 (3) 245251, http://link.springer.com/10.1007/s10643-007-0208-1

Heuer, A. (2013) 'Darwin and the Evolution Revolution: Audiences, Culture, Worldview, Transformative Learning' Leicester: University of Leicester Research Archive https:// Ira.le.ac.uk/handle/2381/28522

Kellert, S. and Wilson, E. (1993) The Biophilia Hypothesis (1st Edn.), Washington D.C: Island Press. 
Kellert, S. (2005) 'Building for Life: Designing and Understanding the Human-Nature Connection' Children and Nature.org, http://www.childrenandnature.org/uploads/ Kellert BuildingforLife.pdf

Kellert, S. (2012) Birthright (1st Edn.), New Haven: Yale University Press.

Kimble, G. (2013) 'Children Learning about Biodiversity at an Environment Centre, a Museum and at Live Animal Shows' Studies in Educational Evaluation, 41 48-57 http://dx.doi.org/10.1016/j.stueduc.2013.09.005

Kirk, E. (2013) 'Gaining Young Children's Perspectives on Natural History Collections' Journal of Natural Science Collections, 1, 138-43.

Kirk, E. (2014) 'Crystal Teeth eggs: Snapshots of Young Children's Experiences in a Natural History Museum' Leicester: University of Leicester Research Archive https://Ira.le.ac. uk/handle/2381/29320

Louv, R. (2010) Last Child in the Woods (1st Edn.) London: Atlantic.

Melber, L. (2007) 'Maternal Scaffolding in two Museum Exhibition Halls' Curator: The Museum Journal, 50 (3) 341-354 http://onlinelibrary.wiley.com/ doi/10.1111/j.2151-6952.2007.tb00276.x/abstract

McGhie, H. (2012) 'Living Worlds at The Manchester Museum' in Stephanie S Jandl and Mark Gold (Eds.) A Handbook for Academic Museums, 220-236, Edinburgh: MuseumsEtc.

Moran, R. (2010) 'Family Matters: The Role of University Museums in Intergenerational Learning' International Committee for University Museums and Collections (UMAC) Proceedings, 2 69-73 http://edoc.hu-berlin.de/docviews/abstract.php?id=30400

Moss, S. (2012) 'Natural Childhood' Nationaltrust.org.uk, http://www.nationaltrust.org.uk/ document-1355766991839/

Nadelson, L. (2013) 'Who is Watching and Who is Playing: Parental Engagement with Children at a Hands-on Science Center' The Journal of Educational Research, 106(6) 478-484 http://www.tandfonline.com/doi/abs/10.1080/00220671.2013.833010

National Trust (2012) 'Reconnecting Children with Nature: Findings of the Natural Childhood Inquiry,' http://www.nationaltrust.org.uk/document-1355773744553/

Oxarart, A., Monroe, M. and Plate, R. (2013) 'From Play Areas to Natural Areas: The Role of Zoos in Getting Families Outdoors' Visitor Studies, 16 (1) 82-94 http://www. tandfonline.com/doi/abs/10.1080/10645578.2013.768074

Palmquist, S. and Crowley, K. (2007) 'From Teachers to Testers: How Parents Talk to Novice and Expert Children in a Natural History Museum' Sci. Ed., 91 (5) 783-804 http://doi.wiley.com/10.1002/sce.20215p

Pascal, C. and Bertram, T (2012) 'Praxis, Ethics and Power: Developing Praxeology as a Participatory Paradigm for Early Childhood Research' European Early Childhood Education Research Journal, 20 (4) 477-492 http://dx.doi.org/10.1080/135029 $\underline{3 x .2012 .737236}$

Phelan, S. and Kinsella, E. (2012) 'Picture this . . Safety, Dignity, and VoiceEthical Research with Children: Practical Considerations for the Reflexive Researcher Qualitative Inquiry, 19 (2) 81-90 http://qix.sagepub.com/cgi/ doi/10.1177/1077800412462987 
Piscitelli, B. and Anderson, D. (2000) 'Young Children's Learning in Museum Settings' Informal Science. Org http://archive.informalscience.org/researches/VSA-a0a6u6-a 5730.pdf

Pretty, J., Angus, C., Bain, M., Gladwell, V., Hine, R., Pilgrim, S., Sandercock, G. and Sellens, M. (2009) 'Nature, Childhood, Health and Life Pathways' Healthy Parks, Healthy People Central, http://www.hphpcentral.com/wp-content/uploads/2010/10/ Nature-Childhood-and-Health-iCES-Occ-Paper-2009-2-FINAL.pdf

Puchner, L., Rapoport, R. and Gaskins, S. (2001) 'Learning in Children's Museums: is it Really Happening?' Curator: The Museum Journal, 44 (3) 237-259 http:// onlinelibrary.wiley.com/doi/10.1111/j.2151-6952.2001.tb01164.x/full.

Robson, C. (2011) Real World Research (3 $3^{\text {rd }}$ edn) Chichester, West Sussex: Wiley.

Royal Society for The Protection of Birds (2010) 'Every Child Outdoors' http://www.rspb.org. uk/Images/everychildoutdoors tcm9-259689.pdf

Tobias, S. (1994) 'Interest, Prior Knowledge, and Learning' Review of Educational Research, 64 (1) 37-54 http://links.jstor.org/sici?sici=0034$6543 \% 28199421 \% 2964 \% 3 A 1 \% 3$ C37\%3AIPKAL\%3E2.0.CO\%3B2V\&origin=crossref

Tunnicliffe, S. and Reiss, M. (2000) 'What Sense Do Children Make of Three-Dimensional, Life-Sized "Representations" of Animals?' School Science and Mathematics, 100 (3) 128-138 http://onlinelibrary.wiley.com/doi/10.1111/j.1949-8594.2000.tb17248.x/full

White, R. and Stoecklin, V. (2008) 'Nurturing Children's Biophilia: Developmentally Appropriate Environmental Education for Young Children' Kansas City MO: White Hutchinson Leisure and Learning Group http://whitehutchinson.cn/children/articles/ downloads/nurturing.pdf

Wood, E. and Wolf, B. (2008) 'Between the Lines of Engagement in Museums: Indiana University and the Children's Museum of Indianapolis' The Journal of Museum Education, 33 (2) 121-130

http://www.jstor.org /stable/pdf/40479637.pdf

Wolf, B. and Wood, E (2012) 'Integrating Scaffolding Experiences for the Youngest Visitors in Museums' Journal of Museum Education, 37 (1) 29-38 http://www.maneyonline. com/doi/abs/10.1179/jme.2012.37.1

Yin, R. (2003). Case study research: design and methods. 3rd ed. Thousand Oaks, Calif.; London: Sage.

\section{Elaine Bates}

Early Years Coordinator

Manchester Museum

Oxford Road

Manchester

M13 9PL

elaine.bates@manchester.ac.uk 